\title{
Organic-inorganic hybrid nanoflowers: types, characteristics, and future prospects
}

\author{
Seung Woo Lee ${ }^{1}$, Seon Ah Cheon ${ }^{1}$, Moon II Kim² and Tae Jung Park"(D)
}

\begin{abstract}
Organic-inorganic hybrid nanoflowers, a newly developed class of flower-like hybrid nanoparticles, have received much attention due to their simple synthesis, high efficiency, and enzyme stabilizing ability. This article covers, in detail, the types, structural features, mechanism of formation, and bio-related applications of hybrid nanoflowers. The five major types of hybrid nanoflowers are discussed, i.e., copper-protein, calcium-protein, and manganese-protein hybrid nanoflowers, copper-DNA hybrid nanoflowers, and capsular hybrid nanoflowers. The structural features of these nanoflowers, such as size, shape, and protein ratio generally determine their applications. Thus, the specific characteristics of hybrid nanoflowers are summarized in this review. The interfacial mechanism of nanoflower formation is examined in three steps: first, combination of metal ion and organic matter; second, formation of petals; third, growth of nanoflowers. The explanations provided herein can be utilized in the development of innovative approaches for the synthesis of hybrid nanoflowers for prospective development of a plethora of hybrid nanoflowers. The future prospects of hybrid nanoflowers in the biotechnology industry, medicine, sensing, and catalysis are also discussed.
\end{abstract}

Keywords: Biosynthesis, Nanoflowers, Organic-inorganic hybrid

\section{Background}

Since the inceptive studies of new nanomaterials in the early 2000s, various nanomaterials with captivating morphologies such as the core-shell structure [1], and Janus particle [2] have been developed. Among these new nanostructures, the topographical features of nanoflowers have piqued the interests of scientists because the higher surface-to-volume ratio in comparison with spherical nanoparticles is beneficial to enhancement in the efficiency of surface reactions. Therefore, extensive studies focusing on the applications of the nanoflowers have been undertaken. Despite the increasing interest in nanoflowers, synthesis of these species requires very harsh conditions such as toxic organic solvents, high temperature, and high pressure. Thus, it is difficult to control their morphological features for tailoring the

\footnotetext{
${ }^{*}$ Correspondence: tjpark@cau.ac.kr

1 Department of Chemistry, Chung-Ang University, 84 Heukseok-ro,

Dongjak-gu, Seoul 06974, Republic of Korea

Full list of author information is available at the end of the article
}

structures of nanoflowers, and it is a formidable task to apply these particles in the field of biochemistry.

Enzymes are biological species with excellent activity and substrate specificity, but their use is limited by certain drawbacks such as high sensitivity to the surrounding environment, low reproducibility of experimental outcomes, and the requirement for complex purification processes. To facilitate application in drug delivery systems or detectors, novel nanomaterials called "nanobiomaterials" have been developed. These are also known as "organic-inorganic hybrid nanomaterials;" the name indicates that all of the inorganic nanoparticle components are bound to organic materials. Current methods for the preparation of nano-biomaterials can be classified into four categories in terms of immobilization [3-6], conjugation [7-9], crosslinking [10-13], and self-assembly [14]. Nano-biomaterials have numerous prospective applications in catalysis [15-18], biosensors [19-22], and drug delivery [23-26].

Proteins as enzymes have a strong affinity for metal ions as cofactor and thus, the stability of proteins is generally enhanced during immobilization onto the metal 
surface by the interaction such as charge affinity, covalent bond, and structural coupling $[27,28]$. However, immobilized proteins exhibit lower activity than the free enzyme, primarily due to the loss of their activity by changing the orientation during the immobilization process and masstransfer limitations on solid supports [29-32]. Singleprotein nanoparticles and nanogels are examples of novel nano-biomaterials that have been used as catalysts with highly preserved activities [3, 10-13]. The activity of enzymes in these nanoparticles and nanogels could be as much as $\sim 60-90 \%$ of that of the free enzymes. In one of the few examples where the activity is better than that of the free enzyme, organophosphorus hydrolase embedded in mesoporous silica demonstrated an activity of $~ 200 \%$ in solution compared with the free hydrolase [33]. In the case of trypsin, which is a hydrolyzing enzyme that can digest itself, its immobilization on a solid support increased the catalytic efficiency by thousands of times compared with that of free trypsin [34]. However, problems such as loss of enzyme properties are still encountered in these complicated processes.

Recently, a new approach for facile and safe synthesis of hybrid nanomaterials was developed to overcome the limitations of conventional methods [35]. Because it is possible to fabricate a nanomaterial simply by adding protein to metal ion solution, this synthetic method does not require any toxic elements or extreme harsh conditions. Therefore, the organic substance involved in the synthesis is subjected to less manipulation compared with other conventional methods to maintain the activity of the immobilized enzyme.

The flower-like hybrid nanomaterials generated by this process are called "organic-inorganic hybrid nanoflowers" or "hybrid nanoflowers". Their synthesis mechanism, physical properties, protein activity, stability, and reproducibility have been intensively studied, and thus far, these species have exhibited significantly better properties than the free enzymes. The feasibility of in vivo application of nanoflowers in protein complexes, medicines, and serological studies is also a topic of investigation. However, a new paradigm shift is required in application of hybrid nanoflowers from enzyme stability improvements and efficient drug delivery systems to new horizons such as cell imaging, biosensor, and medical approaches.

This review presents an overview of several synthetic strategies that have been suggested to diversify nanoflowers, including their structural features. Moreover, the synthesis mechanism is confirmed through analysis. On the basis of experimental and theoretical data, we propose future prospects for novel nanoflowers and their further enhancement.

\section{Types of nanoflowers}

Hybrid nanoflowers can be classified on the basis of the structure of the particles and the type of metal and organic material used. The classifications are summarized in Table 1.

\section{General nanoflowers using copper(II) ions and proteins}

Since the initial development of hybrid nanoflowers consisting of copper(II) ions and proteins, these species have been intensively studied by focusing on their efficiency and stability [35-39]. Because many studies on copperprotein hybrid nanoflowers have been investigated well than those of other hybrid nanoflowers, the synthesis mechanism and applications of copper-protein hybrid nanoflowers are relatively well understood.

Ge et al. [35] first serendipitously discovered the hybrid nanoflower and confirmed that the copper ion and protein create a new type of particle via interaction. Subsequently, they synthesized four types of hybrid nanoflowers using $\alpha$-lactalbumin, laccase, carbonic anhydrase, and lipase, respectively. The synthesized hybrid nanoflowers were used in the detection of phenols and oxidation of catecholamines. Each efficiency of the nanoflowers was found to be the same or superior to (95-650 \%) to those

\section{Table 1 Types of organic-inorganic hybrid nanoflowers}

\begin{tabular}{|c|c|c|c|c|}
\hline & Metal ion & Organic material & Target & References \\
\hline \multirow[t]{4}{*}{1} & \multirow[t]{4}{*}{ Copper } & $\alpha$-Lactalbumin & - & {$[35]$} \\
\hline & & Laccase & \multirow{3}{*}{$\begin{array}{l}\text { Catecholamines, } \\
\text { phenols }\end{array}$} & \\
\hline & & $\begin{array}{l}\text { Carbonic anhy- } \\
\text { drase }\end{array}$ & & \\
\hline & & Lipase & & \\
\hline 2 & Copper & Laccase & Phenol & {$[36]$} \\
\hline 3 & Copper & $\begin{array}{l}\text { Glucose oxidase } \\
\text { and HRPa }\end{array}$ & Glucose & {$[37]$} \\
\hline 4 & Copper & Trypsin & $\mathrm{HRP}^{\mathrm{a}}, \mathrm{BSA}^{\mathrm{b}}$ & [38] \\
\hline 5 & Copper & $\mathrm{HRP}^{\mathrm{a}}$ & $\begin{array}{l}\text { Hydrogen perox- } \\
\text { ide, phenol }\end{array}$ & {$[39]$} \\
\hline 6 & Calcium & $\alpha$-Amylase & Cnp-G3c & {$[44]$} \\
\hline 7 & Calcium & Chitosan & $\begin{array}{l}\text { Hydrogen per- } \\
\text { oxide }\end{array}$ & {$[45]$} \\
\hline \multirow[t]{3}{*}{8} & \multirow[t]{3}{*}{ Manganese } & Immunoglobulin G & \multirow[t]{3}{*}{ Ractopamine } & \multirow[t]{3}{*}[46]{} \\
\hline & & $\begin{array}{l}\text { Anti-ractopamine } \\
\text { ab }\end{array}$ & & \\
\hline & & $\begin{array}{l}\text { Bovine serum } \\
\text { albumin }\end{array}$ & & \\
\hline 9 & Copper & DNA & Specific cell & {$[55]$} \\
\hline 10 & Copper & $\begin{array}{c}\text { Bovine liver } \\
\text { catalase }\end{array}$ & $\begin{array}{l}\text { Hydrogen per- } \\
\text { oxide }\end{array}$ & {$[56]$} \\
\hline
\end{tabular}

\footnotetext{
a Horseradish peroxidase

b Bovine serum albumin

c 2-Chloro-4-nitrophenylmaltotrioside
} 


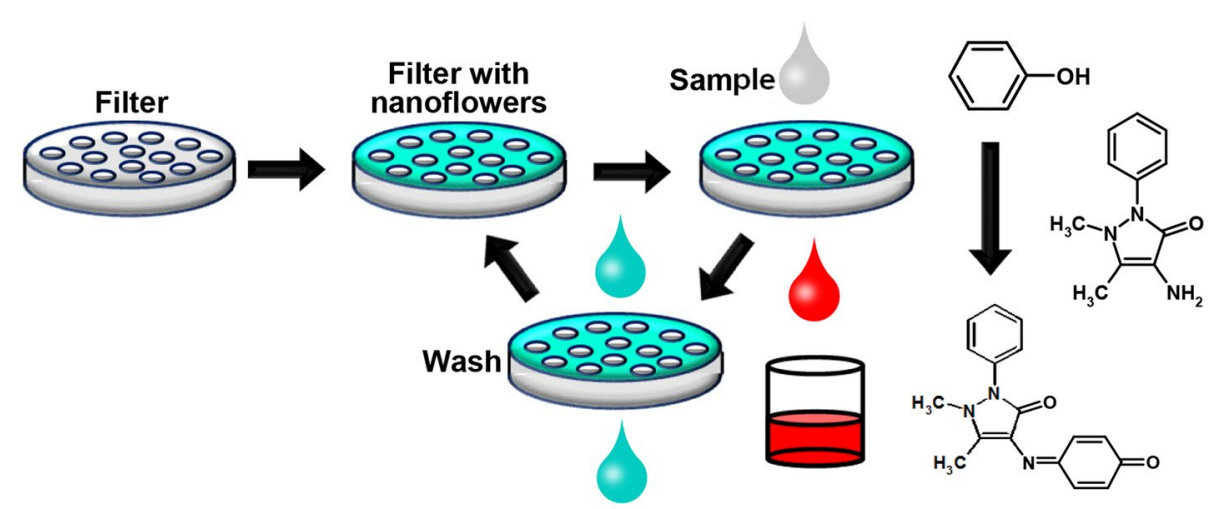

Fig. 1 Application cycle of the membrane with incorporated laccase nanoflowers: fabrication, use, rinse, and reuse. Phenol and ortho-, meta-, and para-substituted phenols react with 4-aminoantipyrine to form colored compounds, which can be easily detected. Reproduced with permission from Ref. [36]: Copyright 2013 Wiley-VCH Verlag GmbH \& Co. KGaA, Weinheim

of the conventional free enzyme solutions. The increased efficiency is derived from the following interplay of factors: (i) the large surface area of the nanoflower which does not cause mass-transfer limitations; (ii) the cooperative interaction of the entrapped enzyme molecules; (iii) the mutual influence of the enzyme and the microenvironment of the nanoflower that contains metal ions on each other (for example, $\mathrm{Cu}^{2+}$ ions in the nanoflowers may enhance the activity of laccase).

Furthermore, the researchers developed a simplified phenol detector comprising a syringe filter containing adsorbed hybrid nanoflowers of laccase [36] (Fig. 1). Briefly, a mixture of aqueous phenol and 4-aminoantipyrine was injected into the nanoflower-coated filter using a syringe and kept in the filter chamber for $5 \mathrm{~min}$. The high activity of laccase entrapped in the nanoflowers enabled rapid oxidative interaction of phenol with 4-aminoantipyrine to generate antipyrine dyes. The final red solution was pushed out of the syringe and collected for analysis by naked-eye visualization or by using a UV/Vis spectrophotometer. The detection rate of this method is faster than that of pre-existing gas chromatography (GC) or liquid chromatography (LC). This method also facilitated the reuse of the filter for about 1 month through cleaning due to the high stability of the enzyme in the particles.

Following this germinal research, Sun et al. synthesized multienzymatic hybrid nanoflowers using glucose oxidase (GOx) and horse-radish peroxidase (HRP) [37], demonstrating the possibility that two or more enzymes could be included in a single hybrid nanoflower. Even to date, most co-immobilizations of multi-enzyme are performed via comparatively complicated processes such as by covalent cross-linking [40], encapsulation [41], gene fusion [42], and post-translational enzyme conjugation [43]. Unfortunately, these techniques are time consuming or result in reduced enzymatic activity, which limits the application of the hybrid materials. As an alternative, the discovery of this novel nanoflower offers a fast and simple synthesis. The procedure used in this experiment (Fig. 2) is as follows: glucose oxidized by GOx generates $\mathrm{H}_{2} \mathrm{O}_{2}$, which is immediately catalyzed by HRP to oxidize $3,3^{\prime}, 5,5^{\prime}$-tetramethylbenzidine (TMB), resulting in a color change from clear to blue. The conventional twostep process generally does not lead to high efficiency owing to the diffusion of $\mathrm{H}_{2} \mathrm{O}_{2}$ generated from glucose oxidation. However, in the hybrid nanoflower, loss of the generated $\mathrm{H}_{2} \mathrm{O}_{2}$ can be reduced because GOx and HRP are simultaneously present, resulting in more accurate detection.

The trypsin hybrid nanoflower synthesized by Lin et al. was used for enhanced protein analysis [38]. Mass spectrometry (MS) used widely for proteomic analysis,

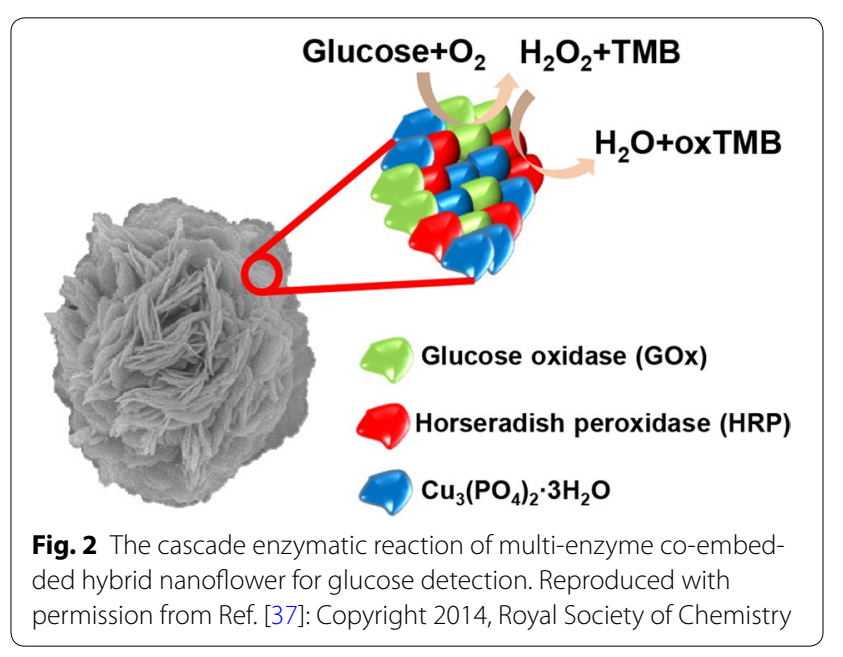


involves analysis of enzymatically digested peptides created from the parent protein. Therefore, effective proteolysis is required as a key step for effective identification of proteins. Generally, proteolysis is performed by using free enzymes, and suffers from some limitations such as long digestion time, autolysis, low stability towards environmental changes, and difficult recovery of products. Enzymes immobilized on solid supports have been used to overcome these disadvantages. The trypsin hybrid nanoflower was first used as an immobilized enzyme by Lin et al. to achieve high proteolytic performance, good enzyme stability and reusability, and a short digestion time [38]. Moreover, the activity of the enzyme component of the hybrid nanoflower was comparable to that achieved in various conventional protein analyses. The favorable results indicate that the hybrid nanoflower is a promising enzyme system for proteomic analysis.

A hybrid nanoflower employing copper ions and HRP for visual detection of hydrogen peroxide and phenol was also synthesized [39]. As above, the hybrid nanoflower was used as a catalyst in the reaction of hydrogen peroxide and phenol in the presence of 4-aminoantipyrine. Changes in the solution color could be detected with concentrations as low as $0.5 \mu \mathrm{M}$ hydrogen peroxide and $1 \mu \mathrm{M}$ phenol by the naked eye. The threshold concentration of hydrogen peroxide to prevent cellular damage is $50 \mu \mathrm{M}$; thus, the limit of detection (LOD) obtained with the use of the hybrid nanoflower meets the requirement for early clinical diagnosis. The LOD for phenol also satisfies the requirements for application to the detection of water pollution. In contrast, the LODs for hydrogen peroxide and phenol using free HRP were $\sim 20$ and $\sim 10 \mu \mathrm{M}$, respectively. The enzyme activity of the HRP hybrid nanoflower is enhanced by the large surface-to-volume ratio that facilitates contact with reactants. Moreover, the reaction time of the HRP hybrid nanoflower $(\sim 5 \mathrm{~min})$ is faster than that of free HRP ( $25 \mathrm{~min})$. The above results revealed that the hybrid nanoflower is more useful for the development of a highly sensitive colorimetric sensing platform.

\section{General nanoflowers using calcium(II) ions and proteins}

Nanoflowers employing calcium ions have also been investigated, even though most nanoflowers are synthesized with the copper ion [44, 45]. A nanoflower employing calcium phosphate crystals was synthesized by Wang et al. by using the same method used for the synthesis of copper nanoflowers [44]. The flower-like morphology was confirmed and a postulate of how the activity increases due to the enzyme immobilization procedure was presented. The $\alpha$-amylase used in this experiment is an enzyme that exhibits allosteric phenomena (Fig. 3a). In the absence of calcium ions, $\alpha$-amylases are usually

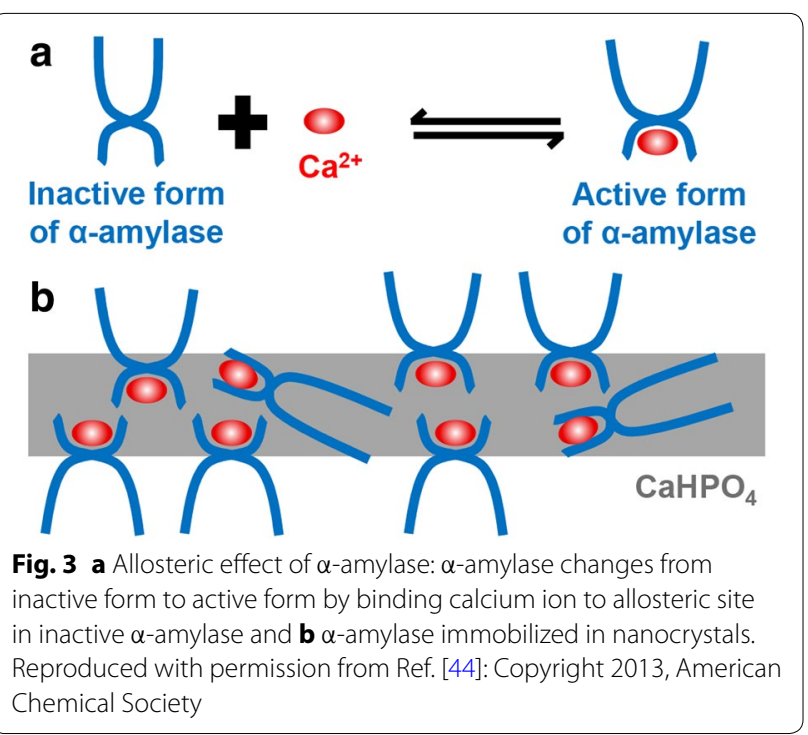

in an inactive state as the functional site is inhibited. In contrast, in the presence of calcium ions, the allosteric sites of $\alpha$-amylase are occupied by the calcium ion, thus affecting the structure of the functional site. During the synthesis of the hybrid nanoflower using calcium ions and $\alpha$-amylase, the calcium ions activate and are strongly bound to $\alpha$-amylase. Because the two elements are located close to each other during the formation of the hybrid nanoflower, $\alpha$-amylase was active for a longer period than the free enzyme, which is randomly and briefly activated by calcium ions (Fig. 3b). Thus, Wang et al. showed that it is essential to understand the chemical interaction between the protein and nanomaterials to improve the functionality of the protein in a given environment [44].

A hybrid nanoflower employing calcium ions was also presented in a recent study [45]. Unlike previous synthesis methods using protein solution, chitosan (CS) and tripolyphosphate (TPP) were used to fabricate a gelform composite via ionic bonding. Although this method has different steps from that used by Hou et al. [44], the mechanism of nanoflower formation is the same (Fig. 4). Calcium ions and TPP form calcium phosphate crystals, and the nanoflower is obtained by the reaction of these crystals and the CS-TPP gel complex. Almost any type of catalyst could be used in this experiment because the catalyst combines with chitosan in the CS-TPP gel complex by electrostatic interaction. However, because addition of the catalyst declined in the nucleation sites for calcium phosphate formation, it should be noted that the maximum amount of catalyst for the formation of the nanoflower was $5.0 \mathrm{mg}$. This technique for nanoflower synthesis provides a new approach that facilitates the 


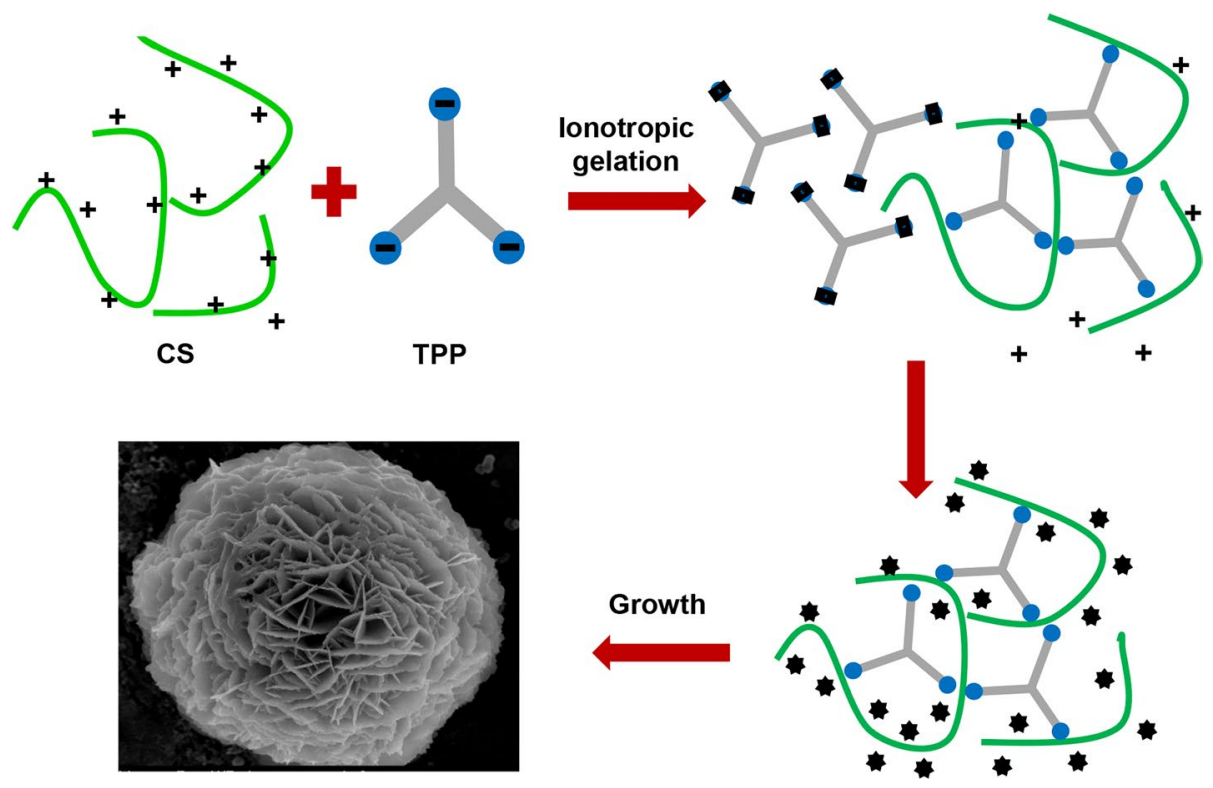

Fig. 4 Schematic synthesis of chitosan-calcium ion hybrid nanoflower. Chitosan binds to pyrophosphate through ionotropic gelation and generates CS-TPP gel complex which reacts with calcium phosphate crystal to form hybrid nanoflower. Reproduced with permission from Ref. [45]: Copyright 2014, American Chemical Society

generation of the nanoflower using a variety of organic substances.

\section{General nanoflowers using manganese(II) ions and proteins}

Manganese phosphate hybrid nanoflowers were synthesized by Zhang et al. to apply into a novel electrochemical biosensor for detection of ractopamine, which can cause acute poisoning consumed by humans [46]. Although many analytical methods have been developed for the detection of ractopamine, such as liquid chromatography-mass spectrometry (LC-MS) [47, 48], gas chromatography-mass spectrometry (GCMS) [49], high-performance liquid chromatography (HPLC) [50], and bioassay [51]. They have some limits owing to high instrument cost and long-time analysis. To solve the problem, electrochemical methods were applied by using the phenolic hydroxyl group, which makes ractopamine electrochemically active [52]. However, this detection method was also limited that due to its low response activity on electrode surfaces. Hybrid nanoflower as a novel electrochemical biosensor overcomes the disadvantage. These nanoflowers are made by manganese(II) ions and three types of protein, immunoglobulin G (IgG), ractopamine antibody (RACanti), and bovine serum albumin (BSA) (Fig. 5). The detection limits of the developed electrochemical biosensors

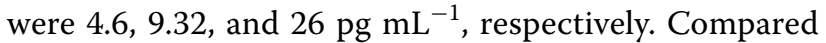
with the detection limits of previous different methods, these results present that electrochemical methods using hybrid nanoflowers are more sensitive [52-54]. This study shows that the hybrid nanoflower can be used as electrochemical tools as well as catalyst or drug delivery matter.

\section{General nanoflowers using copper(II) ion and DNA}

$\mathrm{Hu}$ et al. used DNA as the organic material instead of protein in hybrid nanoflowers [55]. Because DNA is highly soluble in aqueous medium and has a high content of nitrogen atoms in its structure like protein, it could be used in the synthesis of hybrid nanoflowers by binding metal ions. The DNA hybrid nanoflower morphology was combined with the fluorescence resonance energy transfer (FRET) phenomenon to obtain high-resolution images of cells or to use for traceable drug delivery systems. In brief, the researchers created a site in the DNA template for the simultaneous attachment of a drug and fluorescent dyes (FAM, CY3, ROX), and subsequently, they synthesized a hybrid nanoflower coupled to the fabricated DNA by rolling circle replication (RCR) with the metal ions (Fig. 6). Consequently, they were able to obtain a high-resolution image based on FRET between the dyes using long-wavelength light, which does not affect the cells. Furthermore, the path of drug delivery in the living cells was successfully traced by monitoring the light emitted by the dyes. Thus, $\mathrm{Hu}$ et al. suggested that DNA hybrid nanoflowers can be applied in many fields by showing the feasibility of the synthesis of DNA hybrid nanoflowers [55]. 


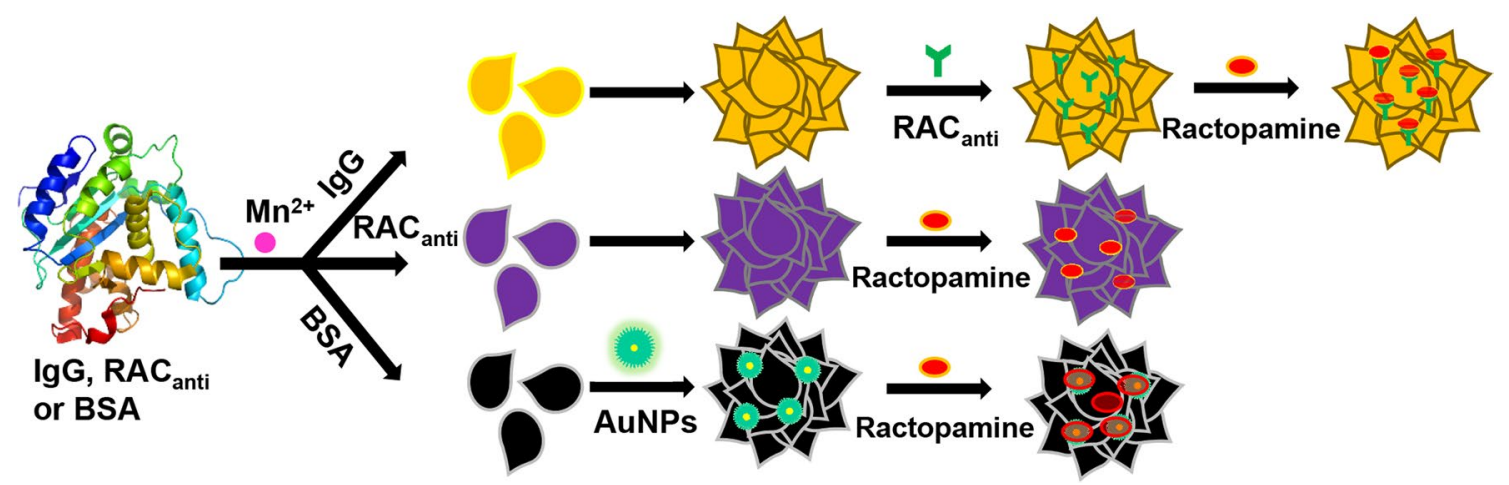

Fig. 5 Schematic representation of the synthesis of manganese-based hybrid nanoflowers as a novel electrochemical biosensor for the detection of ractopamine, including (i) $\mathrm{Mn}_{3}\left(\mathrm{PO}_{4}\right)_{2}-\mathrm{lgG}$, (ii) $\mathrm{Mn}_{3}\left(\mathrm{PO}_{4}\right)_{2}-\mathrm{RAC}_{\text {anti }}$ (anti-ractopamine antibody), and (iii) $\mathrm{Mn}_{3}\left(\mathrm{PO}_{4}\right)_{2}$ - $\mathrm{BSA}$-Au nanoflowers. Reproduced with permission from Ref. [46]: Copyright 2015, Elsevier

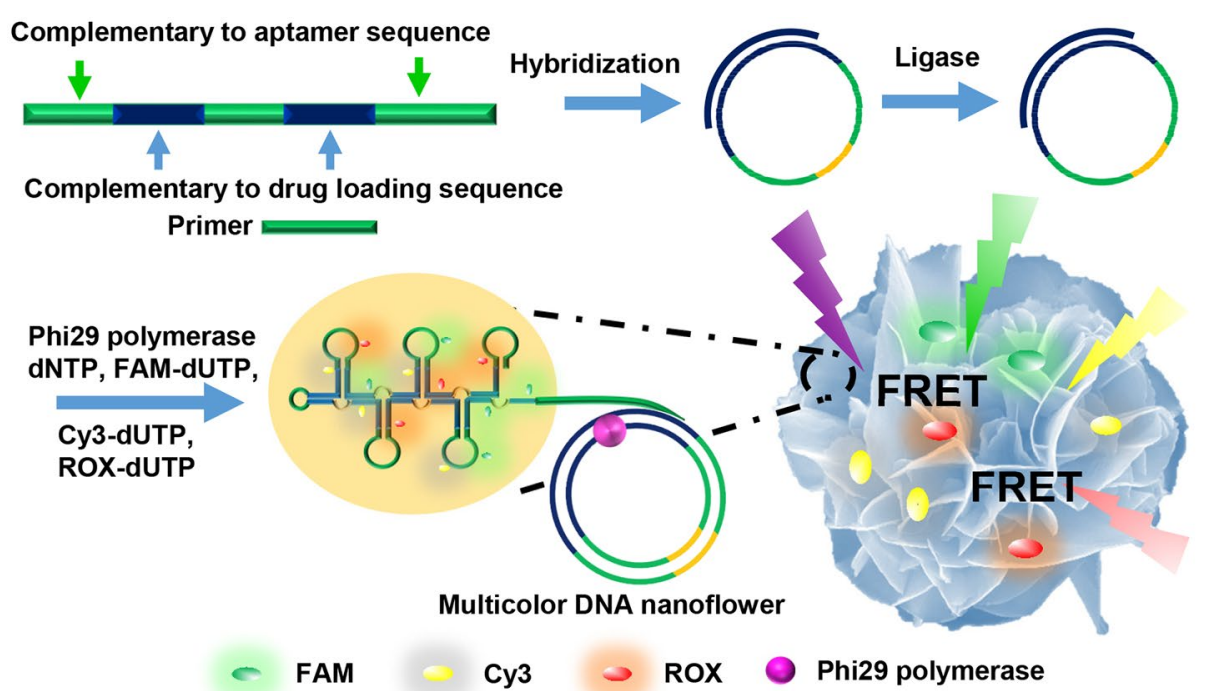

Fig. 6 Sequence-independent self-assembly of multicolor FRET (fluorescence resonance energy transfer) DNA hybrid nanoflower. Reproduced with permission from Ref. [55]: Copyright 2014, Wiley-VCH Verlag

\section{Capsular nanoflowers using copper(II) ions and proteins}

A capsular nanoflower was synthesized by Jiang and coworkers, as shown in Fig. 7 [56, 57]. Compared with early hybrid nanoflowers synthesized from a metal phosphate and protein, the capsular nanoflower was synthesized by an additional wrapping with protamine and silica through a biomimetic mineralization approach and removing the metal from the core. Because the rough surface of the multiple shells facilitates the adsorption of substrates, the capsular nanoflower exhibited significantly enhanced enzyme activity as well as better stability under extreme conditions (high temperature, $\mathrm{pH}$, long-term storage) than simple hybrid nanoflowers. These properties provide a practicable and useful solution for enhancing the efficiency in bio-chemical applications such as catalysis and drug delivery.

\section{Characteristics}

\section{Structural features and enzyme efficiency}

As shown in Table 2, the hybrid nanoflowers can be classified based on characteristics such as shape, size, protein/total weight ratio percent, and enzyme efficiency compared to that of the free enzyme.

Although the size of hybrid nanoflowers varies depending on the protein concentration, the range of variation is narrow (about $\pm 3 \mu \mathrm{m}$ ). Thus, based on the average size from optimized data, the nanoflowers range from 2 to $30 \mu \mathrm{m}$, and the pore size (which is the diameter of the 


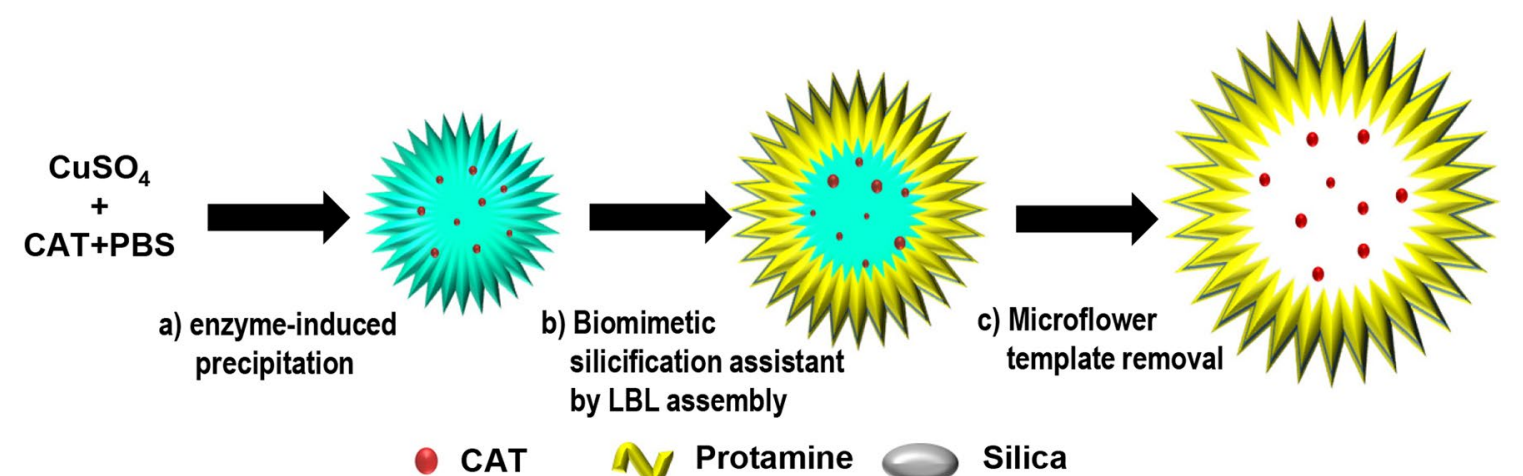

Fig. 7 Scheme of preparation procedure of the FPSH capsules: a formation of protein-inorganic hybrid microflowers; $\mathbf{b}$ formation of (protaminesilica) 2 bilayers on the microflowers; $\mathbf{c}$ formation of the FPSH capsules after eliminating the microflower template through EDTA treatment. Reproduced with permission from Ref. [56]: Copyright 2014, The Royal Society of Chemistry

hole between petals) is approximately $0.1 \mu \mathrm{m}$. Because the size of most of these hybrid flowers is expressed in micro units $(\mu \mathrm{m})$, we believe that the use of the term "microflower" is more correct than "nanoflower." In addition, the shape of the hybrid nanoflowers is similar to that of round flowers, but with subtle variations. Thus, the pictures that resembles the respective scanning electron microscopy (SEM) images are provided to highlight the differences (Table 2).

The weight ratio of protein to total particle weight measured by thermogravimetric analysis (TGA) is also summarized in Table 2, demonstrating that the protein constitutes $10-66 \%$ of the total weight. Furthermore, as more protein is used, the percentage of protein increases. However, the encapsulation efficiency (the ratio of the amount of immobilized protein to the total amount of protein employed) follows a completely opposite trend. Excessive addition of protein to a constant weight of inorganic component induces a dramatic decrease of the encapsulation efficiency. In light of these considerations, the proper amount of protein must be selected to conserve the protein and to attain good morphology and a high weight percentage.

Finally, we consider the enzyme efficiency of hybrid nanoflowers. Compared with the corresponding free enzyme solutions, the enzyme efficiency of hybrid nanoflowers varies from 85 to over $1000 \%$. These results suggest that the proteins in hybrid nanoflowers have higher activity and stability than the corresponding free enzyme solutions despite immobilization in the flower petals. Moreover, hybrid nanoflowers overcome the previously encountered problem of mass-transfer limitation and open up an avenue for application to various research and detection fields.

\section{Mechanism}

The mechanism for the synthesis of organic-inorganic hybrid nanoflowers comprises three steps (Fig. 8). In the early growth step, primary crystals of metal phosphate $\left[\mathrm{M}_{3}\left(\mathrm{PO}_{4}\right)_{2},(\mathrm{M}: \mathrm{Cu}, \mathrm{Ca})\right]$ are formed. At this stage, the organic molecules (protein, DNA) form complexes with the metal ions $\left(\mathrm{Cu}^{2+}, \mathrm{Ca}^{2+}\right)$, mainly through coordination via the amide groups in the protein backbone. These complexes provide a location for nucleation of the primary crystals. In the second growth stage, metal-protein crystals aggregate into large agglomerates of protein molecules and primary petals are formed. The kinetically controlled growth of metal phosphate crystals originates on the surfaces that have the $\mathrm{Cu}^{2+}$ binding sites of these agglomerates, causing flower-like petals to appear in the embryo. In the final step, anisotropic growth leads to complete formation of a branched flower-like structure. In this growth process, the protein induces nucleation of the metal phosphate crystals to form the scaffold for the petals and serves as a "glue" to bind the petals together. In the absence of the proteins, large crystals, but no nanoflowers, are formed.

\section{Future prospects}

In the 1960s, the development of enzyme immobilization technology inspired chemists to design new biomaterials containing highly stabilized enzymes. However, immobilization generally led to loss of the enzyme activity. By the 1990s, the activity of enzymes immobilized on nanosized materials could be maintained at levels up to that of the free enzymes. Interest in this field was again awakened with the unearthing of the first organic-inorganic hybrid nanoflower in 2012, and many studies focusing on new flower-like hybrid nanomaterials are still in progress. 
Table 2 Characteristics of organic-inorganic hybrid nanoflowers

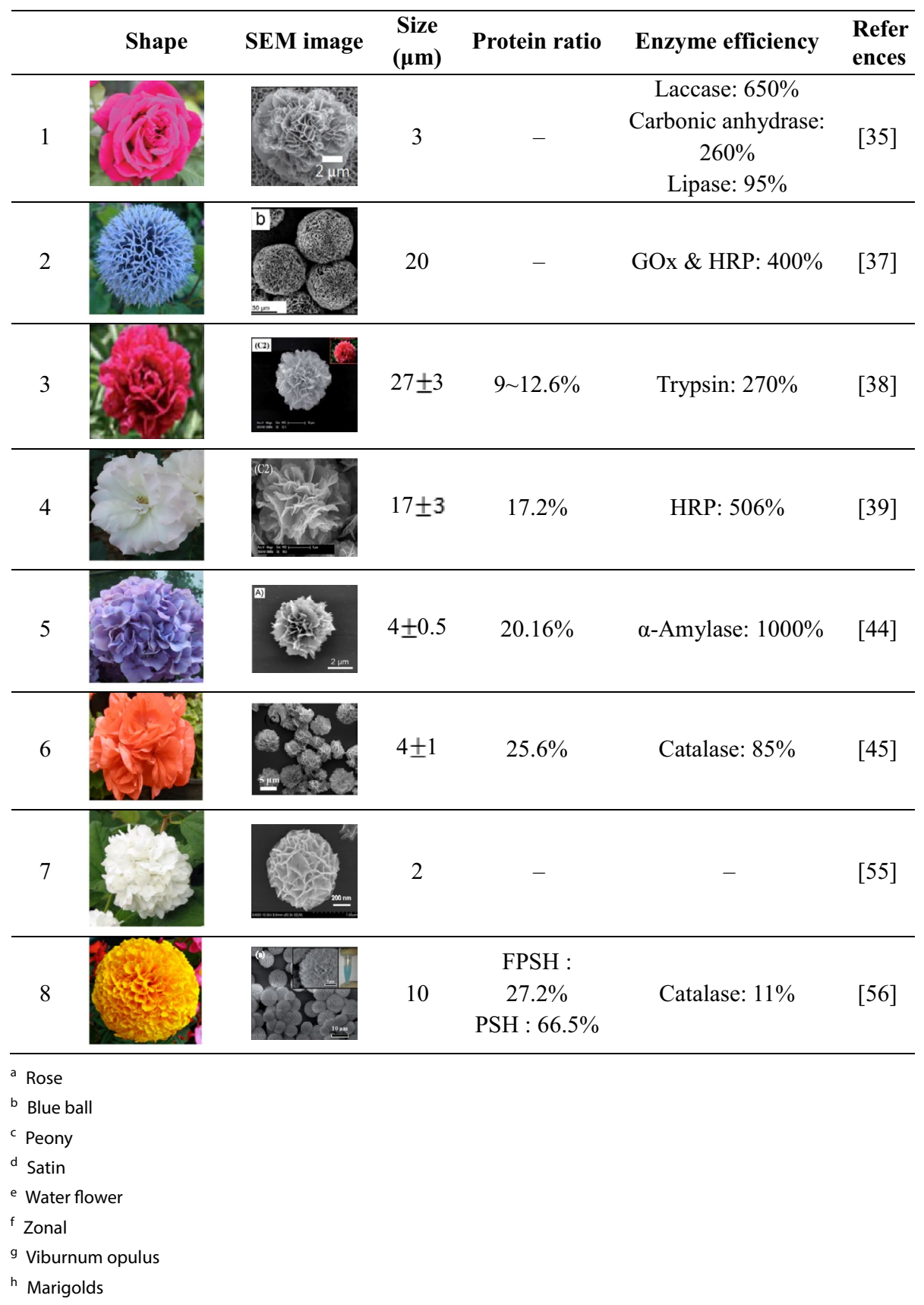

Future research for the development of drug delivery systems, biosensors, biocatalysts, and bio-related devices is anticipated to take multiple directions. New synthesis principles, new types of hybrid nanoflowers, and detailed mechanisms are expected to emerge. The application of nanoflowers in bio-catalysis and enzyme mimetics, tissue engineering, and the design of highly sensitive biosensing kits, as well as industrial bio-related devices with advanced functions, various and controllable syntheses, biocompatibility, and modifications of hybrid nanoflower structures and properties, should receive increasing attention.

\section{Conclusions}

In summary, organic-inorganic hybrid nanoflowers have piqued the interest of researches and numerous related papers have been published. Research in this field is spurred by the simplicity of the synthesis and safe 


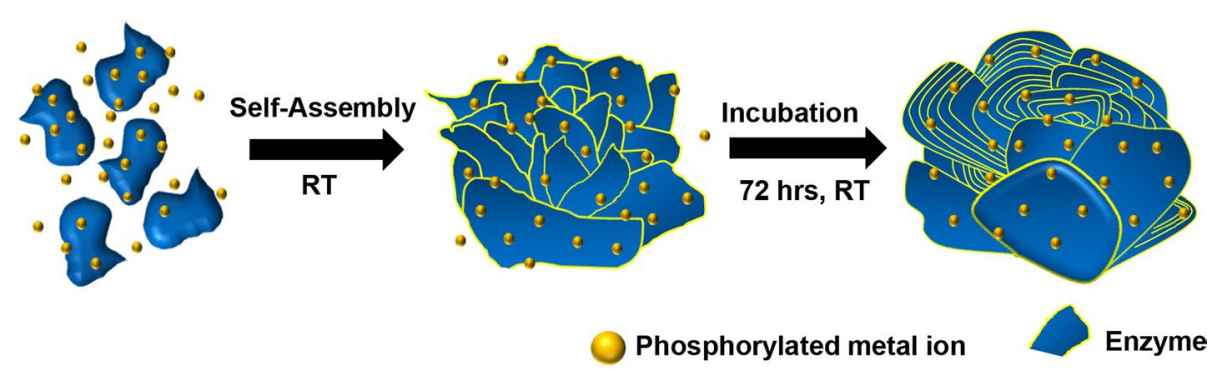

Fig. 8 Synthesis mechanism of organic-inorganic hybrid nanoflower. Reproduced with permission from Ref. [35]: Copyright 2012, Nature Publishing Group

conditions. Moreover, high efficiency and enzyme stability are readily achieved with hybrid nanoflowers. We believe that the study of organic-inorganic hybrid nanoflowers will lead to creative solutions and rapid development of biomaterials and biotechnology industries.

\section{Abbreviations}

GOx: glucose oxidase; HRP: horse-radish peroxidase; LOD: limit of detection; CS: chitosan; TPP: tripolyphosphate; SEM: scanning electron microscopy.

\section{Authors' contributions}

SWL and TJP conceived the idea of the work and performed the checking the cited references. SAC and MIK were reviewed and commented the manuscript. All authors contributed to the preparation of the manuscript and commented on the final version. All authors read and approved the final manuscript.

\section{Author details}

'Department of Chemistry, Chung-Ang University, 84 Heukseok-ro, Dongjak-gu, Seoul 06974, Republic of Korea. ${ }^{2}$ Department of BioNano Technology, Gachon University, 1342 Seongnamdaero, Sujeong-gu, Seongnam-si, Gyeonggi-do 461-701, Republic of Korea.

\section{Acknowledgements}

This research was supported by the Advanced Production Technology Development Program, Ministry of Agriculture, Food and Rural Affairs (312066-3), a grant of the Korean Health Technology R\&D Project, Ministry of Health \& Welfare, Republic of Korea (H113C0862) and the Chung-Ang University Graduate Research Scholarship in 2015.

\section{Compliance with ethical guidelines}

\section{Competing interests}

The authors declare that they have no competing interests.

Received: 5 August 2015 Accepted: 25 August 2015

Published online: 04 September 2015

\section{References}

1. Schärtl W. Crosslinked spherical nanoparticles with core-shell topology. Adv Mater. 2000;12(24):1899-908.

2. Lattuada M, Hatton TA. Synthesis, properties and applications of Janus nanoparticles. Nano Today. 2011;6(3):286-308.

3. Kim J, Grate JW. Single-enzyme nanoparticles armored by a nanometerscale organic/inorganic network. Nano Lett. 2003;3(9):1219-22.

4. Dyal A, Loos K, Noto M, Chang SW, Spagnoli C, Shafi KV, et al. Activity of Candida rugosa lipase immobilized on $\gamma$ - $\mathrm{Fe}_{2} \mathrm{O}_{3}$ magnetic nanoparticles. Am Chem Soc. 2003;125(7):1684-5.
5. Asuri P, Karajanagi SS, Dordick JS, Kane RS. Directed assembly of carbon nanotubes at liquid-liquid interfaces: nanoscale conveyors for interfacial biocatalysis. J Am Chem Soc. 2006;128(4):1046-7.

6. Ji PJ, Tan HS, Xu X, Feng W. Lipase covalently attached to multiwalled carbon nanotubes as an efficient catalyst in organic solvent. AIChE J. 2010;56(11):3005-11.

7. Abuchowski A, McCoy JR, Palczuk NC, van Es T, Davis FF. Effect of covalent attachment of polyethylene glycol on immunogenicity and circulating life of bovine liver catalase. J Biol Chem. 1977;252(11):3582-6.

8. Ehrat M, Luisi PL. Synthesis and spectroscopic characterization of insulin derivatives containing one or 2 poly(ethylene oxide) chains at specific positions. Biopolymers. 1983;22(1):569-73.

9. Boyer C, Bulmus V, Liu J, Davis TP, Stenzel MH, Barner-Kowollik C. Welldefined protein-polymer conjugates via in situ RAFT polymerization. J Am Chem Soc. 2007;129(22):7145-54.

10. Yan M, Ge J, Liu Z, Ouyang P. Encapsulation of single enzyme in nanogel with enhanced biocatalytic activity and stability. J Am Chem Soc. 2006;128(34):11008-9.

11. Ge J, Lu D, Wang J, Yan M, Lu Y, Liu Z. Molecular fundamentals of enzyme nanogels. J Phys Chem B. 2008;112(45):14319-24.

12. Ge J, Lu D, Wang J, Liu Z. Lipase nanogel catalyzed transesterification in anhydrous dimethyl sulfoxide. Biomacromolecules. 2009;10(6):1612-8.

13. Yan M, Liu Z, Lu D, Liu Z. Fabrication of single carbonic anhydrase nanogel against denaturation and aggregation at high temperature. Biomacromolecules. 2007;8(2):560-5.

14. Shen L, Bao N, Prevelige PE, Gupta A. Fabrication of ordered nanostructures of sulfide nanocrystal assemblies over self-assembled genetically engineered P22 coat protein. J Am Chem Soc. 2010;132(49):17354-7.

15. Kouassi GK, Irudayaraj J, McCarty G. Examination of Cholesterol oxidase attachment to magnetic nanoparticles. J Nanobiotechnology. 2005;3(1):1

16. Prakasham RS, Devi GS, Rao CS, Sivakumar VS, Sathish T, Sarma PN. Nickelimpregnated silica nanoparticle synthesis and their evaluation for biocatalyst immobilization. Appl Biochem Biotechnol. 2010;160(7):1888-95.

17. Ding $H$, Wen $L$, Chen J. Porous silica nano-tube as host for enzyme immobilization. China Particuol. 2004;2(6):270-3.

18. Ansari SA, Husain Q. Potential applications of enzymes immobilized on/in nano materials: a review. Biotechnol Adv. 2012;30(3):512-23.

19. Wang R, Tian Z, Chen L. Nano-encapsulations liberated from barley protein microparticles for oral delivery of bioactive compounds. Int J Pharm. 2011;406(1-2):153-62.

20. Kumar PS, Ramakrishna S, Saini TR, Diwan PV. Influence of microencapsulation method and peptide loading on formulation of poly(lactide-coglycolide) insulin nanoparticles. Pharmazie. 2006;61(7):613-7.

21. Wanakule P, Liu GW, Fleury AT, Roy K. Nano-inside-micro: disease-responsive microgels with encapsulated nanoparticles for intracellular drug delivery to the deep lung. J Control Release. 2012;162(2):429-37.

22. Kim JK, Anderson J, Jun HW, Repka MA, Jo S. Self-assembling peptide amphiphile-based nanofiber gel for bioresponsive cisplatin delivery. Mol Pharm. 2009;6(3):978-85.

23. Njagi J, Andreescu S. Stable enzyme biosensors based on chemically synthesized Au-polypyrrole nanocomposites. Biosens Bioelectron. 2007;23(2):168-75. 
24. Lin J, Qu W, Zhang S. Disposable biosensor based on enzyme immobilized on Au-chitosan-modified indium tin oxide electrode with flow injection amperometric analysis. Anal Biochem. 2007;360(2):288-93.

25. Zhang YW, Zhang Y, Wang H, Yan B, Shen GL, Yu RQ. An enzyme immobilization platform for biosensor designs of direct electrochemistry using flower-like $\mathrm{ZnO}$ crystals and nano-sized gold particles. J Electroanal Chem. 2009;627(1-2):9-14.

26. Takhistov P. Electrochemical synthesis and impedance characterization of nano-patterned biosensor substrate. Biosens Bioelectron. 2004;19(11):1445-56.

27. Sassolas A, Blum LJ, Leca-Bouvier BD. Immobilization strategies to develop enzymatic biosensors. Biotechnol Adv. 2012;30(3):489-511.

28. Datta S, Christena LR, Rajaram YRS. Enzyme immobilization: an overview on techniques and support materials. Biotech. 2012;3(1):1-9.

29. Kim J, Grate JW, Wang P. Nanobiocatalysis and its potential applications. Trend Biotechnol. 2008;26(11):639-46.

30. Ge J, Lu DN, Liu ZX, Liu Z. Recent advances in nanostructured biocatalysts. Biochem Eng J. 2009;44(1):53-9.

31. Luckarift HR, Spain JC, Naik RR, Stone MO. Enzyme immobilization in a biomimetic silica support. Nat Biotechnol. 2004;22(2):211-3.

32. Mateo C, Grazu V, Palomo JM, Lopez-Gallego F, Fernandez-Lafuente R, Guisan JM. Immobilization of enzymes on heterofunctional epoxy supports. Nat Protoc. 2007;2(5):1022-33.

33. Lei $C$, Shin Y, Liu J, Ackerman EJ. Entrapping enzyme in a functionalized nanoporous support. J Am Chem Soc. 2002;124(38):11242-3.

34. Dulay MT, Baca QJ, Zare RN. Enhanced proteolytic activity of covalently bound enzymes in photopolymerized sol gel. Anal Chem. 2005;77(14):4604-10.

35. Ge J, Lei J, Zare RN. Protein-inorganic hybrid nanoflowers. Nat Nanotechnol. 2012;7(7):428-32.

36. Zhu L, Gong L, Zhang Y, Wang R, Ge J, Liu Z, Zare RN. Rapid detection of phenol using a membrane containing laccase nanoflowers. Chem Asian J. 2013;8(10):2358-60.

37. Sun J, Ge J, Liu W, Lan M, Zhang H, Wang P, et al. Multi-enzyme coembedded organic-inorganic hybrid nanoflowers: synthesis and application as a colorimetric sensor. Nanoscale. 2014;6(1):255-62.

38. Lin Z, Xiao Y, Wang L, Yin Y, Zheng J, Yang H, et al. Facile synthesis of enzyme-inorganic hybrid nanoflowers and their application as an immobilized trypsin reactor for highly efficient protein digestion. RSC Adv. 2014;4(27):13888-91.

39. Lin Z, Xiao Y, Yin Y, Hu W, Liu W, Yang H. Facile synthesis of enzyme-inorganic hybrid nanoflowers and its application as a colorimetric platform for visual detection of hydrogen peroxide and phenol. ACS Appl Mater Interf. 2014;6(13):10775-82.

40. Manesh KM, Santhosh P, Uthayakumar S, Gopalan Al, Lee KP. One-pot construction of mediatorless bi-enzymatic glucose biosensor based on organic-inorganic hybrid. Biosens Bioelectron. 2010;25(7):1579-86.

41. Delaittre G, Reynhout IC, Cornelissen JJ, Nolte RJ. Cascade reactions in an all-enzyme nanoreactor. Chem Eur J. 2009;15(46):12600-3.

42. Fan Z, Wagschal K, Chen W, Montross MD, Lee CC, Yuan L. Multimeric hemicellulases facilitate biomass conversion. Appl Environ Microbiol. 2009;75(6):1754-7.
43. Hirakawa H, Kamiya N, Tanaka T, Nagamune T. Intramolecular electron transfer in a cytochrome P450cam system with a site-specific branched structure. Protein Eng Des Sel. 2007;20(9):453-9.

44. Wang LB, Wang YC, He R, Zhuang A, Wang X, Zeng J, et al. A new nanobiocatalytic system based on allosteric effect with dramatically enhanced enzymatic performance. J Am Chem Soc. 2013;135(4):1272-5.

45. Wang X, Shi J, Li Z, Zhang S, Wu H, Jiang Z, et al. Facile one-pot preparation of chitosan/calcium pyrophosphate hybrid microflowers. ACS Appl Mater Interf. 2014;6(16):14522-32.

46. Zhang Z, Zhang Y, Song R, Wang M, Yan F, He L, et al. Manganese(II) phosphate nanoflowers as electrochemical biosensors for the high-sensitivity detection of ractopamine. Sens Actuat B Chem. 2015;211:310-7.

47. Blanca J, Munoz P, Morgado M, Mendez N, Aranda A, Reuvers T, et al. Determination of clenbuterol, ractopamine and zilpaterol in liver and urine by liquid chromatography tandem mass spectrometry. Anal Chim Acta. 2005;529(1-2):199-205.

48. Shishani E, Chai SC, Jamokha S, Aznar G, Hoffman MK. Determination of ractopamine in animal tissues by liquid chromatography-fluorescence and liquid chromatography/tandem mass spectrometry. Anal Chim Acta. 2003;483(1-2):137-45

49. He L, Su Y, Zeng Z, Liu Y, Huang X. Determination of ractopamine and clenbuterol in feeds by gas chromatography-mass spectrometry. Anim Feed Sci Technol. 2007;132(3-4):316-23.

50. Shelver WL, Smith DJ. Determination of ractopamine in cattle and sheep urine samples using an optical biosensor analysis: comparative study with HPLC and ELISA. J Agric Food Chem. 2003;51(13):3715-21.

51. Liu M, Ning BA, Qu LJ, Peng Y, Dong JW, Gao N, et al. Development of indirect competitive immunoassay for highly sensitive determination of ractopamine in pork liver samples based on surface plasmon resonance sensor. Sens Actuat B Chem. 2012;161(1):124-30.

52. Wu C, Sun D, Li Q, Wu KB. Electrochemical sensor for toxic ractopamine and clenbuterol based on the enhancement effect of graphene oxide. Sens Actuat B Chem. 2012;168:178-84.

53. Duan JH, He DW, Wang WS, Liu YC, Wu HP, Wang YS, et al. Glassy carbon electrode modified with gold nanoparticles for ractopamine and metaproterenol sensing. Chem Phys Lett. 2013;574:83-8.

54. Jin W, Yang G, Shao H, Qin A. A label-free impedimetric immunosensor for detection of 1-aminohydantoin residue in food samples based on sol-gel embedding antibody. Food Control. 2014;39:185-91.

55. Hu R, Zhang X, Zhao Z, Zhu G, Chen T, Fu T, et al. DNA nanoflowers for multiplexed cellular imaging and traceable targeted drug delivery. Angew Chem Int Ed. 2014;53(23):5821-6.

56. Shi JF, Zhang SH, Wang XL, Yang C, Jiang ZY. Preparation and enzymatic application of flower-like hybrid microcapsules through a biomimetic mineralization approach. J Mater Chem B. 2014;2(27):4289-96.

57. Li J, Jiang ZY, Wu H, Zhang L, Long LH, Jiang YJ. Constructing inorganic shell onto LBL microcapsule through biomimetic mineralization: a novel and facile method for fabrication of microbioreactors. Soft Matter. 2010;6(3):542-50.

\section{Submit your next manuscript to BioMed Central and take full advantage of:}

- Convenient online submission

- Thorough peer review

- No space constraints or color figure charges

- Immediate publication on acceptance

- Inclusion in PubMed, CAS, Scopus and Google Scholar

- Research which is freely available for redistribution

Submit your manuscript at

www.biomedcentral.com/submit
C Biomed Central 